Sains Malaysiana 49(5)(2020): 1137-1144

http://dx.doi.org/10.17576/jsm-2020-4905-19

\title{
Circular Track Finding using Hough Transform with Discretized Polling
}

(Penemuan Jejak Bulatan menggunakan Transformasi Hough dengan Peninjauan Diskret)

\author{
Khasmidatul Akma Mohammad Kamal Azmi*, Wan Ahmad Tajuddin Wan Abdullah, Au DiYa Fatihah \\ \& MOHAMMAD SIDDIQ
}

\begin{abstract}
The objective of this paper was to show the results of single-parameter track finding based on the Hough transform method with discretized hits in an arbitrarily-sized Hough space. Each arbitrarily-sized Hough space was used to identify the most optimal hits with respect to a simulation-generated track. These hits will be useful in future studies involving multiple tracks as an identification of single-track potential size which will decrease the computational steps required to identify potential hits in multiple-track studies. These steps are well established in track finding research. However, the discretized method has not been applied fully because of uncertainty in identifying true hits in the Hough space. We have observed that by selecting the optimal discretized size, we can significantly improve the identification of true hits as it reduces the number of unrelated hits. We show that these steps are a more insightful technique compared to the traditional clustering technique by comparing our results to the K-Mean nearest neighbour method.
\end{abstract}

Keywords: Accumulator; Hough transform; K-Mean; optimal peak; track finding

\section{ABSTRAK}

Objektif kajian ini adalah untuk memperlihatkan hasil penemuan jejak satu-parameter berdasarkan kaedah transformasi Hough dengan hit yang diskret dalam ruang Hough dalam beberapa saiz tertentu. Setiap ruang Hough dengan saiz berbeza digunakan untuk mengenal pasti hits paling optimum berkenaan dengan jejak yang dihasilkan simulasi. Kajian hit ini akan berguna dalam kajian masa depan yang melibatkan pelbagai jejak sebagai pengenalan ukuran potensi satu hit yang akan mengurangkan langkah pengiraan yang diperlukan untuk mengenal pasti hits yang berpotensi dalam jejak berganda. Langkah ini dihasilkan dalam penyelidikan mencari penyelesaian. Walau bagaimanapun, kaedah diskret belum digunakan sepenuhnya kerana ketidakpastian dalam mengenal pasti hits sebenar di dalam ruang Hough. Kami telah melihat bahawa dengan memilih saiz diskret yang optimum, kami dapat meningkatkan pengenalan hits sebenar dengan ketara berbanding jumlah hit yang tidak berkaitan. Kami menunjukkan bahawa langkah ini adalah teknik yang lebih mendalam berbanding teknik berkelompok tradisi dengan membandingkan hasil kami dengan kaedah jiran terdekat Min K.

Kata kunci: Carian jejak; Min K; pengumpulan; puncak optimal; transformasi Hough

\section{INTRODUCTION}

Paul introduced the Hough transform as such in 1962. It was developed in connection with the study of particle track through the viewing field of a bubble chamber. It was one of the first attempts to automate a visual inspection task previously requiring hundreds of man-hours to execute. The Hough transform is one of the notable algorithms which is used for global pattern recognition. Since it is a well-known and straightforward algorithm, it is suitable to evaluate the efficiency of our CDC in several hypotheses of the background conditions. The classic Hough Transform is a standard algorithm for line and circle detection. It can be applied to many computer vision problems as most images contain feature boundaries which can be described by regular curves. The main advantage of the Hough transform technique is that it is tolerant of gaps in feature boundary descriptions and is relatively unaffected by image noise, unlike edge detectors.

By its definition, the Hough transform has limited perceptual scope. Its greatest strength lies in specialized vision, such as manufacturing quality control, analysis of aerial photographs, and data analysis in particle physics. Its well-intentioned application was in particle physics for detection of lines, and arcs in the photographs obtained in cloud chambers. The Hough Transform (HT) falls into the midrange of the vision-processing hierarchy. The method attributes a logical label set of parameter values defining a line or quadric to an object that, until then, existed as a collection of pixels. Therefore, it can be viewed as a segmentation procedure. The idea behind the method is simple: Parametric shapes 
in an image are detected by looking for accumulation points in the parameter space. If a particular shape is present in the image, then the mapping of all of its points into the parameter space must cluster around the parameter values which correspond to that shape. This approach maps distributed and separate elements of the image into a localized accumulation point. The image analysis, the technique used for characteristic extraction is the Hough Transform. The function of this technique is to find an imperfect position of subjects within certain shapes by a scanning and voting procedure. This voting procedure is carried out in a parameter space, also known as the accumulator space. These spaces are built by the algorithm to compute the Hough transform, from which object candidates are obtained as local maxima. The discretized value in the accumulated space is then transformed from the experimental observation to Hough space, which is more readable (Hough 1962).

Our stand-alone Monte Carlo simulation can be implemented in the Central Drift Chamber (CDC) environment for the track-finding of charged particle coordinate positions. The main reason to use Hough transformation techniques is because they are much more suitable for tracing a charged particle or signal in any of the trajectory patterns, based on the optional parameter values used. The objective of this paper was to report the simulation results of the singletrajectory parameters track pattern and how it can work with different case studies for real track finding in experimental data in future.

This paper is organized as follows: Firstly, we give a general description of Hough transform, an explanation about the diagram on how the data, and describe the Monte Carlo algorithm used in space discretization and polling to find the actual parameter in Hough space. We then show that the result of our method using the Monte Carlo model can be used to detect the pattern of tracks from the Hough transform then continuely with the clustering with K-Mean.

\section{DETECTION IN HOUGH SPACE}

The understanding on Hough transform assume a set of points into which a line can be fitted. A line in 2D Cartesian coordinates can be represented by the standard equation

$$
y=a x+b
$$

The transformation of a line into Hough space is carried out by applying the formula

$$
r=x \cos \theta+y \sin \theta
$$

In a 2D space, a circular Hough can be described by:

$$
(x-a)^{2}+(y-b)^{2}=r^{2}
$$

where $(a, b)$ is the center of the circle, and $r$ is the radius. If a $2 \mathrm{D}$ point $(\mathrm{x}, \mathrm{y})$ is fixed, then the parameters can be found according to (3). The parameter space would be three dimensional, $(\mathrm{a}, \mathrm{b}, \mathrm{r})$, and all parameters that satisfy $(x, y)$ would lie on the surface of an inverted right-angled cone whose apex is at ( $\mathrm{x}, \mathrm{y}, 0)$. In 3D space, the circle parameters can be identified by the intersection of many conic surfaces that are defined by points on the 2D circle. This process can be divided into two stages. The first stage is fixing the radii then finding the optimal center of circles in a $2 \mathrm{D}$ parameter space. The second stage is to find the optimal radii in a one-dimensional parameter space.

Shape detection is an essential part of pattern recognition. However, the direct finding of and the detection of the class of even simple geometric patterns such as straight lines, circles, or ellipses are computationally intensive. Hough introduced his transform as a method to convert the problem of global curve detection into an efficient peak detection in parameter space. Rosenfeld popularized it in mainstream computer vision research by giving the first algebraic form for the transform and proposing a simple digital implementation of the Transform space as an array of counters (Priyanka \& Bidyut 2015).

For line detection in $3 \mathrm{D}$, an appropriate parametric line representation needs to be chosen. The line representation of $a+t b$, where $a$ is a point on the line and $b$ (with $b=1$ ) is the direction of the line is redundant and leads to a five-dimensional parameter space. One way to reduce the space and time complexity is a hierarchical approach that first searches for peaks in the slope parameter space, which is only two dimensional, and then further investigates these peaks in the intercept parameter space, which is also two dimensional (Bhattacharya et al. 2000).

\section{HOUGH TRANSFORMATION IN THIS CASE STUDY}

In this work, we implemented the Hough method to scan the maximal peak parameter in the Hough space. The input of this research study is based on the ihit points (points in the study identified as parameters) to generate a single-track subroutine. In this section we will briefly explain how the diagram of experimental study was used for this Hough algorithm. The ihits in this study are defined as cloud point distributions in the Hough space. The maximal peak of ihits is significant to the potential parameters that we compare with the actual parameter value. In this study, the size of the Hough space defines the resolution of the binning size which in turn affects the maximal peak of each parameter.

\section{THE K-MEAN IN THIS CASE STUDY}

From article by Imad (2018), the K-Mean algorithm is an iterative algorithm that tries to partition the data set into $\mathrm{K}$ per-defined distinct clusters where each data point belongs to only one group. It attempts to make the inter-cluster data points as similar as possible while also 
conformity the clusters as different or far as possible. It assigns data points to a cluster such that the sum of the squared distance between the data points and the cluster's centroid (arithmetic mean of all the data points that belong to that cluster) is at the minimum. The less variation we have within clusters, the more homogeneous to the data points are within the same cluster. The algorithm K-Mean by charge $\mathrm{k}$ empty clusters and for each cluster, choose at random a data point making the coordinates of this point the center of the cluster. Proceed by iterating over each data point and calculate which cluster it is closes to and adding the point to closest cluster. When this is done, recalculate the center of each cluster by taking the mean of the assigned points. Continue this process until the centers of the clusters no longer changes. It will continue until the centers of the clusters no longer change (Ahmed 2019).

\section{METHODS}

We firstly took the input signal from a random generator. At present, the implementation of single-track finding parameters is still under investigation. The beginning procedure of this framework is to get the input signal from the random generator. These hits will be the reference points to reconstruct a single track. Diagram 1 shows the flow diagram of the study. The trajectory pattern of the track that we studied is typical for a CDC environment in an experimental set up.

Firstly, we studied how the size of each Hough space affects the discretization of each ihits, i.e. how it has been scanned and stored. Secondly, the maximal peak of each point was discretized to transform it into the Hough space. Lastly is the comparison between the generated track and the reconstruction track which can be carried out with different resolutions and Hough arbitrary sizes.

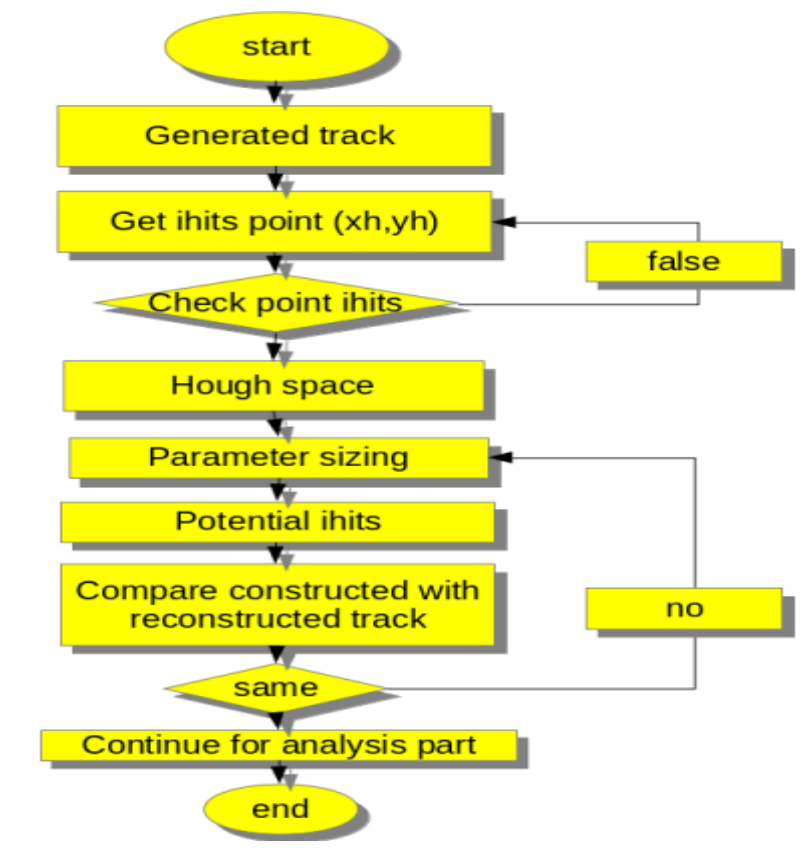

DIAGRAM 1 . The flowchart of the signal track trajectory analysis

A coordinate parameter track pattern is established in the model algorithm by fixing a reference point and using it as the origin position of all ihit points. During the identification or sensing state, a 3D binning space is used as an accumulator, called the Hough Scanning Space (HSS) or Hough parameter space. The ihit points vote for the hypothetical reference point in the HSS according to their resolution space and the corresponding Hough scanning entries in each Hough space. If the potential ihit is identical to the coordinate parameters track pattern, then the cell in the accumulator will match the reference point that obtains the highest number of votes. The peak value would be determined as equal to the reference points when the results from voting and the reference parameters match perfectly.

After the scanning poll in the Hough space, the average of the MINHOUGH variable was calculated to compare with the results from the Hough space candidates. Meanwhile, we also plotted the K-Mean clustering to see the results of the potential ihit candidates 
based on the Hough scanning in each of the resolution space sizes.

\section{RESULTS AND DISCUSSION}

The primary purpose of this case study was to see how the algorithm of Hough transformation with polling in a Hough accumulator will find the actual parameter in specific environments. There are two main parts to this, the first is to consider how the accuracy of the Hough implementation compares with the actual parameter and the second is to see how the binning resolution impacts the finding of the parameters. The comparison of the Monte Carlo parameter with the Hough transformation calculation gives a very significant value for each Hough space that we studied.

From most of the different-sized Hough spaces that we studied, similar patterns of the distribution of the points were seen. As the different sizes of Hough space gave the significance, the resolution of Hough space will be presented to find the right position of the parameter.

From Figure 1, with a Hough space size of 1.0 $\mathrm{cm}$, we can see there are a few differences with each of the parameters compared. The mean of the distribution of points in the Hough peak cannot gives the actual parameter size. However, in the distribution of points, it has the same parameter that we are looking for. It is shown that the peak of the Hough transformation will give the significance value of the parameter. However, the problem of how to choose the perfect parameter needs to be resolved.

According to the study from Krahe and Pousset (1988), a major problem with Hough transform arises from the effects of image quantization, uniform parameter space sampling, and discretization, which make the distributions of parameters non-homogeneous. This is aggravated by the presence of sensor noise and optical distortions, resulting in a spread of votes around the actual bin in the parameter space and leads to inaccuracy in peak detection, as we found in this study.

Based on Figure 2, applying a K-Mean Clustering algorithm to each of the arbitrary Hough spaces gave an idea of the original track pattern respective to the original pattern from the Hough transform. The cluster means inside each group are required as boundaries to the peak hits value. This step of K-Mean has the advantages that it can find all parameters in any pattern and investigate these with a high level of accuracy. Thus, we can see the necessity of assuming lane boundaries of the hits pattern based on the clustering results.
Distribution of 1 st trial size 1.0 for Hough Space Resolution

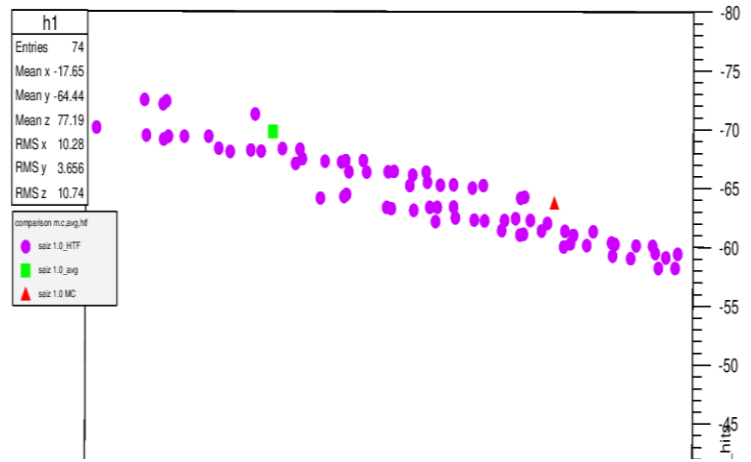

Distribution of $1^{\text {st }}$ trial size 1.75 for Hough space Resolution

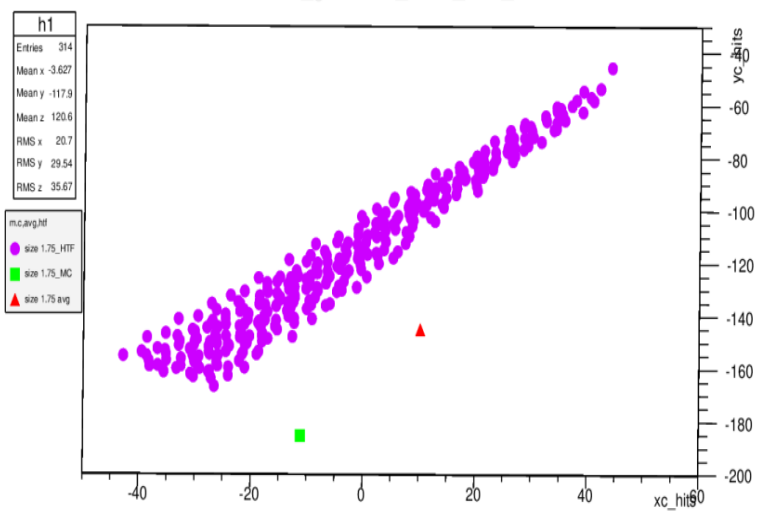

Distribution of 1st trial size 1.5 for Hough Space Resolution

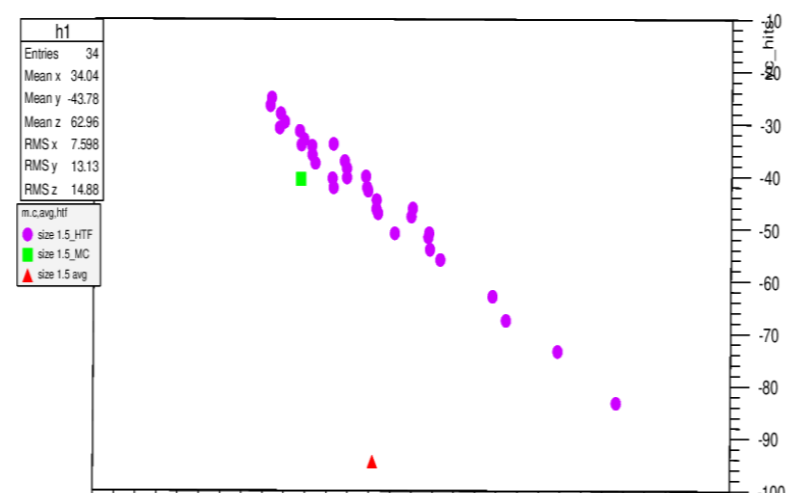

Distribution of 1 st trial size 2.75 for Hough Space Resolution

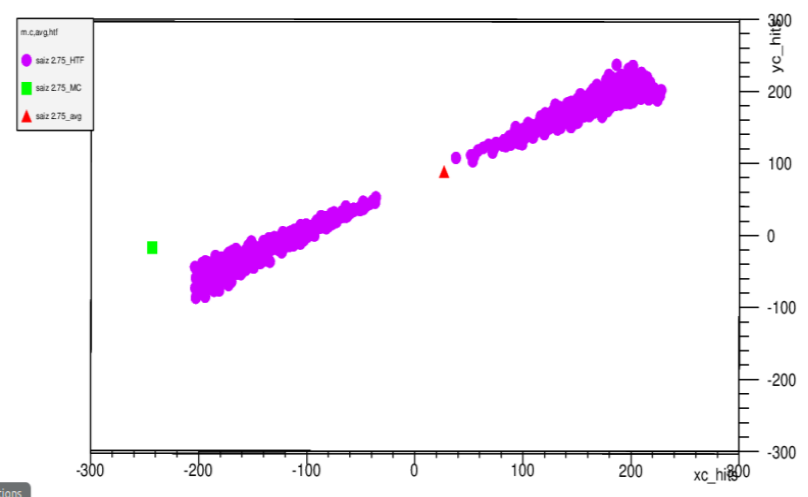


Distribution of 1st trial size 2.5 for Hough Space Resolution

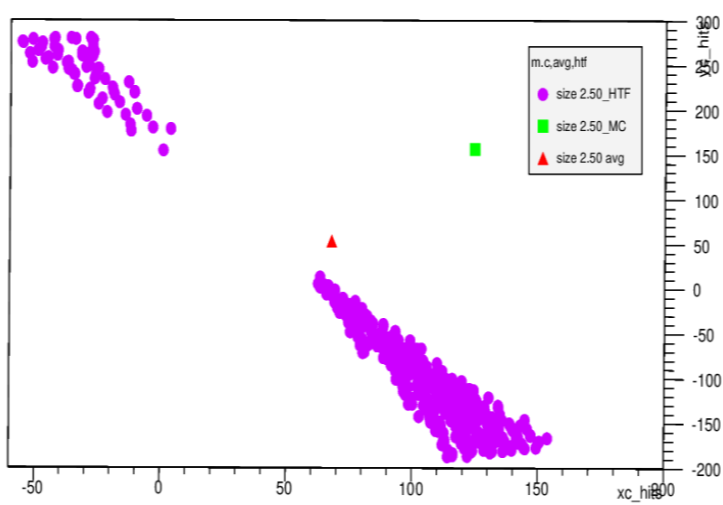

Distribution of 1st trial size 2.0 for Hough Space Resolution

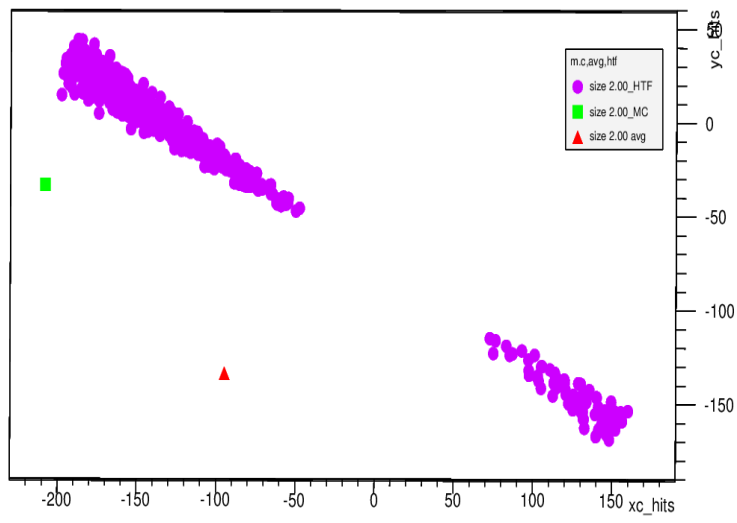

FIGURE 1. Distribution of 1 st trial size $1.0-2.75 \mathrm{~cm}$ for Hough space resolution

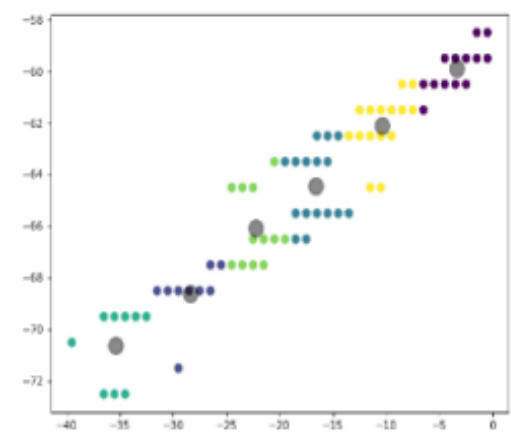

a) K-Mean clustering size 1.0

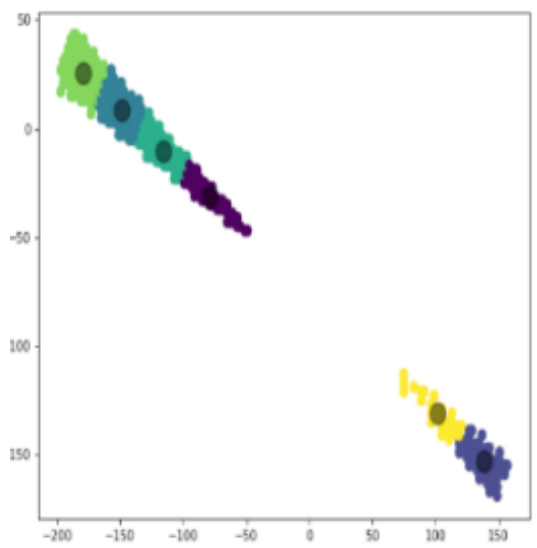

d) K-Mean clustering 2.00

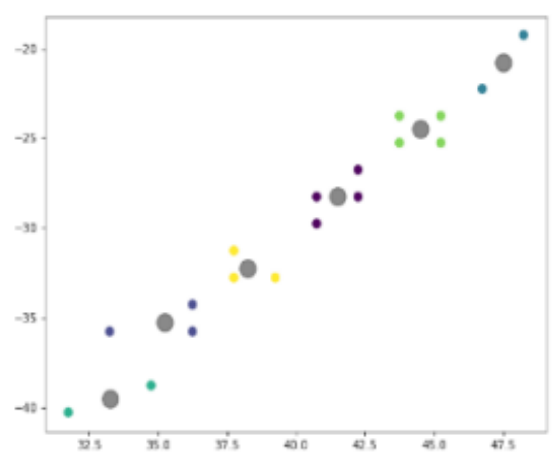

b) K-Mean clustering size 1.5

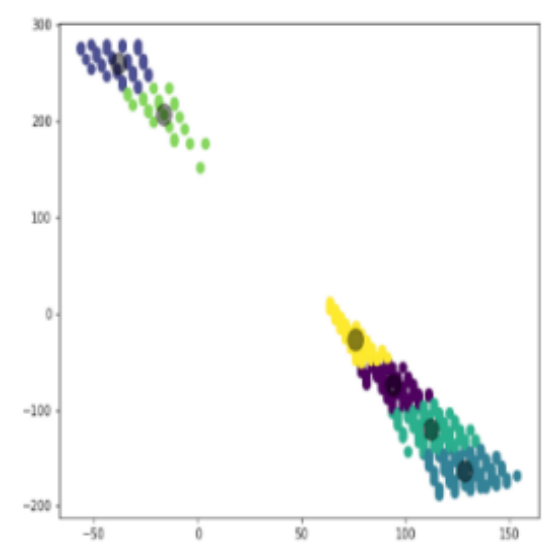

e) K-Mean clustering 2.50

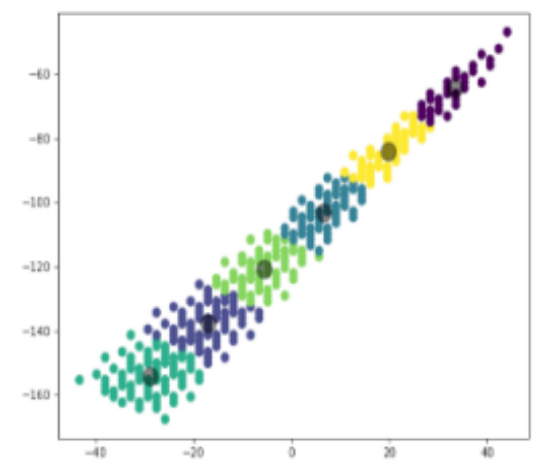

c) K-Mean clustering 1.75

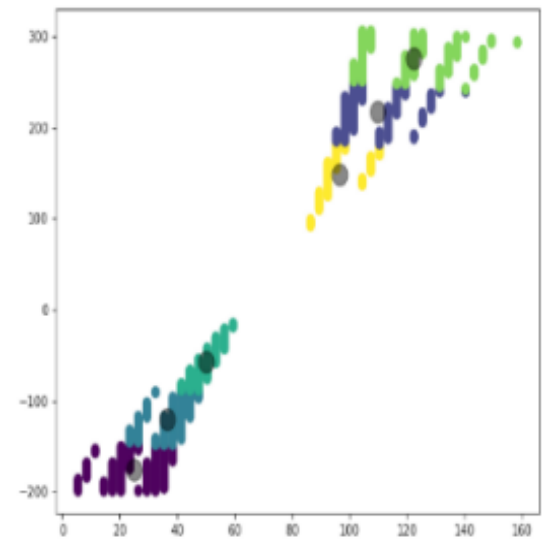

f) K-Mean clustering 2.75

FIGURE 2. K-Mean clustering for sizes $1.0-2.75 \mathrm{~cm}$ in Hough resolution bins

The distribution of K-Mean in Figure 2 show the clustering of the potential point of hits. Meanwhile, this result show that the $\mathrm{K}$ Mean clustering did not give any significant finding after the Hough Transfrom step. There are just the same pattern with the distribution of
Hough Transfrom but did not give improvement of this algorithm. This distribution did not classify the potential hit with any outsanding performance. However, with this K-Mean, it will give the prove that the potential hit found with the Hough Transfrom algorithm. 


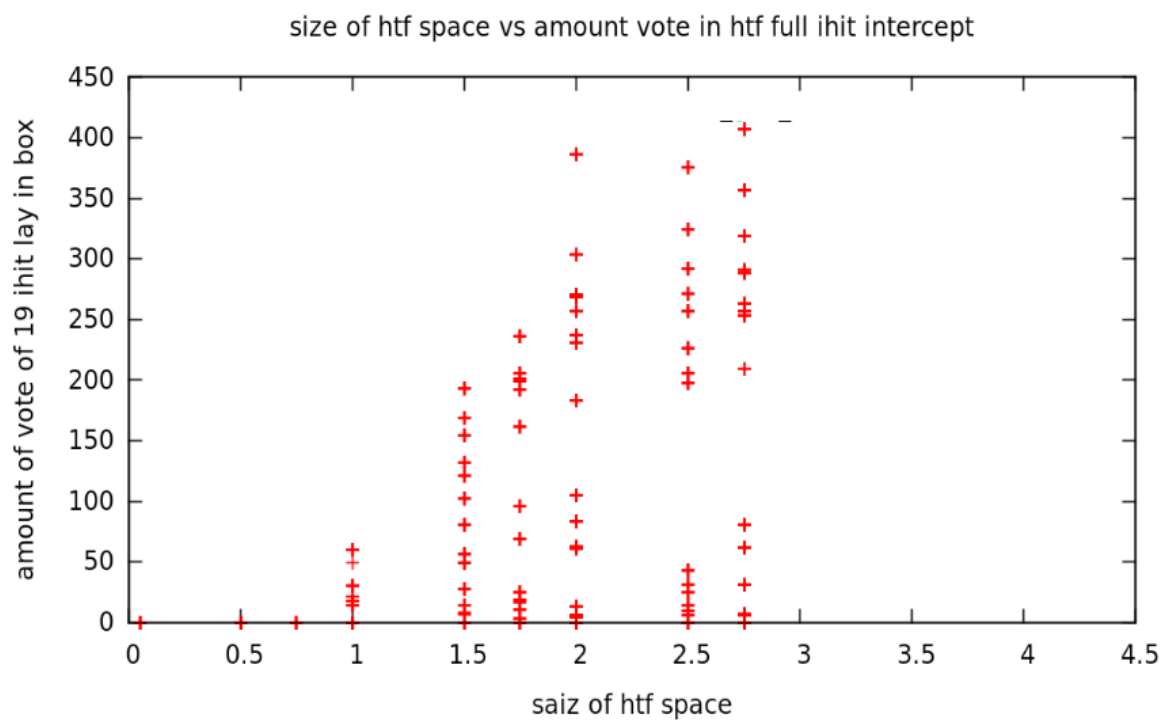

FIGURE 3. A histogram of the distribution of all sizes used in the study against potential ihit candidates in the different Hough spaces

Figure 3 shows the results of the distribution of votes in the Hough space with different sizes. We can see the bigger sizes of Hough space included a lower potential ihits and also unexpected values which should not be included in the district bin size.

TABLE 1. The comparison of each Hough space size from $1.0 \mathrm{~cm}$ to $2.75 \mathrm{~cm}$

\begin{tabular}{ccccccc}
\hline Parameter & Value $1.0 \mathrm{~cm}$ & Value $1.5 \mathrm{~cm}$ & Value $1.75 \mathrm{~cm}$ & Value $2.0 \mathrm{~cm}$ & Value $2.5 \mathrm{~cm}$ & Value $2.75 \mathrm{~cm}$ \\
\hline Entries & 18 & 74 & 314 & 464 & 458 & 595 \\
Mean x & 40.33 & -17.65 & -3.627 & -98.66 & 87.27 & -13.51 \\
Mean y & -29.67 & -64.44 & -117.9 & -19.86 & -57.01 & 65.37 \\
Mean z & 44.58 & 77.19 & 120.6 & 141.4 & 172.2 & 174.7 \\
RMS x & 4.632 & 10.28 & 20.7 & 101.2 & 51.43 & 151.8 \\
RMS y & 5.755 & 3.656 & 29.54 & 56.69 & 129.2 & 103.2 \\
RMS z & 7.028 & 10.74 & 35.67 & 41.39 & 53.6 & 57.16 \\
\hline
\end{tabular}

TABLE 2. The standard deviation Hough for the size $1.0 \mathrm{~cm}$

\begin{tabular}{cccc}
\hline Parameters $1.0 \mathrm{~cm}$ & Monte Carlo & Average Hough transform & Standard deviation Hough (MINHOUGH) \\
\hline $\mathrm{xc}$ & -3.385865 & -17.648648 & 0.648238 \\
$\mathrm{yc}$ & -59.732727 & -64.689189 & \\
$\mathrm{rc}$ & 62.293891 & 77.189189 \\
\hline
\end{tabular}


Each of the different Hough sizes we used showed some pattern in how the potential value accumulated in the binning space. From Figure 1, we can see that the optimal size for this case study was a Hough space of size $1.0 \mathrm{~cm}$. Figure 1 shows how the potential of ihits have been placed and can be found with this method. It shows the potential candidates which had been filtered and the candidates in the resolution size 1.0 $\mathrm{cm}$ have the minimize potential hits at maximal peak. Alexiev (2000) studied the influence of Hough parameter space granularity upon probability of track detection is analyzed, this is the prove that the selected parameter space in Hough in this paper give the minimal noise in the searching of potential hits for this algorithm.

Tables 1 and 2 show a few of the statistical value of distribution that shown the size of $1.00 \mathrm{~cm}$ give the

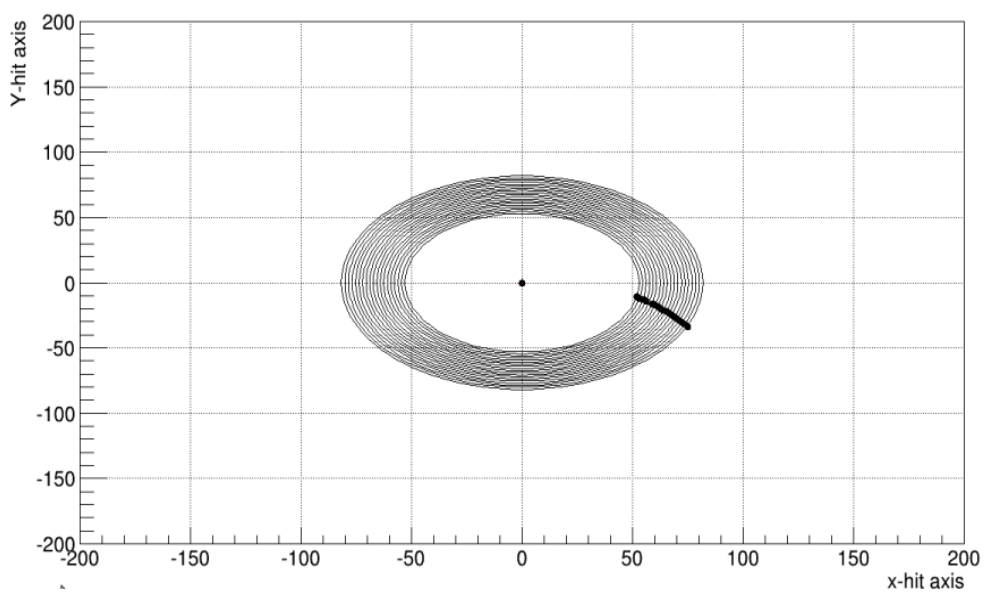

FIGURE 4. Show the result of hit for the size $1.0 \mathrm{~cm}$ in the sense wire layer

good result of finding for this algorithm suggested for this case study. Based on the Figures 1 and 2 of the distribution of potential ihits in each Hough space, we can conclude that the accumulator of size $1.0 \mathrm{~cm}$ gave the best option for study case we have chosen.

Figure 4 shows the example of the result from the reconstruct by the Hough Transform to find the hits for the track to be reconstructed. This show that the potential hits can be found with this method if the Hough space can be significantly choose with the algorithm that we suggest. Each of the layer represent one hit as the simulate from the real diagram stucture for this case study. In is shown in Figure 4, that it might be useful for the future track finding for experimental experiment which the potential ihits can be found with this algorithm.

\section{CONCLUSION}

Our method suggests that the voting in the district polling with different Hough space sizes depends on the scale and orientation of the Hough space. The polling process is based on the frequency of ihits in each of the different sizes of Hough space. Our method is able to detect the track pattern; however, the significance of the potential candidate parameters and the filtering noise are still to be investigated. The peak corresponds to the accumulation of votes computed from randomly selected variable sizes. The algorithm extracts the peak voting in the Hough space. The peak returns a pattern that intersects the potential values of many hit points. Finally, the algorithm evaluates the number of the data hits points of the parameters corresponding to the actual constructed track pattern.

\section{ACKNOWLEDGEMENTS}

The authors acknowledge the financial support provided by the MYBrain15 Malaysia sponsorship and Design and Construction to Discovery: Machine Learning Algorithms for Particle Physics Triggering and Tracking with GPUs and FPGAs in Malaysia (Grant No. IF0032019) for the research.

\section{REFERENCES}

Ahmed, S.R.A., Al Barazanchi, I., Jaaz, Z.A. \& Abdulshaheed, H.R. 2019. Clustering algorithms subjected to K-mean and gaussian mixture model on multidimensional data set. Periodicals of Engineering and Natural Sciences 7(2): 448-457.

Alexiev, K. 2000. Implementation of hough transform as track detector. In Proceedings of the Third International Conference on Information Fusion. Volume 2. pp. THC4-11.

Bhattacharya, P., Liu, H., Rosenfeld, A. \& Thompson, S. 2000. Hough-transform detection of lines in 3-D space. Pattern 
Recognition Letters 21(9): 843-849.

Imad Dbbura. 2018. K-means clustering-algorithm, applications, evaluation methods, and drawbacks. https:// towardsdatascience.com/k-means-clustering-algorithmapplications-evaluation-methods-and-drawbacksaa03e644b48a.

Krahe, J. \& Pousset, P. 1988. The detection of parallel straight lines with the application of the Hough transform. 9th International Conference on Pattern Recognition, Rome, Italy.

Hough, P.V.C. 1962. A method and means for recognizing complex patterns. U.S. Patent: 3,069,654
Priyanka Mukhopadhyay \& Bidyut Baran Chaudhuri 2015. A survey of Hough Transform. Pattern Recognition 48(3): 993-1010.

National Centre for Particle Physics

University of Malaya

50603 Kuala Lumpur, Federal Territory

Malaysia

*Corresponding author; email: khasmidatul@siswa.um.edu.my

Received: 20 September 2019

Accepted: 23 January 2020 